\title{
MICROCLIMA DE AMBIENTES CAVERNÍCOLAS: ESTUDO DE CASO DA GRUTA DA SANTA, PARQUE ESTADUAL DE INTERVALES, SP ${ }^{1}$
}

\author{
ROCHA, Bárbara Nazaré - ba_nrocha@yahoo.com.br \\ Departamento de Geografia - FFLCH-USP.
}

\author{
GALVANI, Emerson - egalvani@usp.br \\ Departamento de Geografia - FFLCH-USP
}

\begin{abstract}
Resumo. Este estudo tem como objetivo caracterizar o microclima da gruta da Santa do Parque Estadual de Intervales, SP, em condições naturais e na presença de turistas. Para isso, foram coletados dados de temperatura e umidade relativa do ar a cada seis minutos por meio de registradores automáticos. Os dados foram comparados ao de uma estação meteorológica instalada no meio externo. Também foi medida a concentração de gás carbônico da gruta. A gruta da Santa se caracteriza por uma estabilidade térmica e hídrica em seu interior, praticamente sem influências do meio externo, já que a caverna não apresenta claraboias, nem rio de águas caudalosas. A concentração de gás carbônico aumenta na medida em que se adentra na cavidade, com amplitudes máximas de $126 \mathrm{ppm}$. Na presença de um pequeno grupo de visitantes (três pessoas), as condições microclimáticas da caverna permaneceram estáveis, 0 que demonstra ausência de impactos na atmosfera cavernícola decorrentes da visitação turística. Esta pesquisa deve contribuir para melhor compreensão desse ambiente tão peculiar e de microclima ainda pouco estudado.

Palavras-chave: microclima, caverna, temperatura do ar, umidade relativa do ar, gás carbônico.

MICROCLIMATE OF CAVE ENVIRONMENTS: CASE STUDY OF GRUTA DA SANTA, INTERVALES STATE PARK-SP

Abstract: The objective of this study is to characterize the microclimate of the grotto of the Saint (gruta da Santa) of the State Park of Intervales (Parque Estadual de Intervales), SP, in natural conditions and in the presence of tourists. For this, temperature and relative humidity of air data were collected by automatic loggers and compared with a meteorological station installed in the external way. Also the carbonic gas concentration of the cave was measured.

This cave is characterized for a thermal and humidity stability in its interior, practically without influences of the external way. The carbonic gas concentration is higher in the cave compared to the external way, with $126 \mathrm{ppm}$ maximum amplitude. In the presence of a small group of visitors, the microclimatic conditions of the cave had remained steady, which demonstrates absence of impacts in the cave atmosphere. This research must contribute for better understanding of this unique environment and its microclimate.
\end{abstract}

Key-words: microclimate, cave, air temperature, relative humidity of air, carbon dioxide.

\section{Introdução}

"O ambiente cavernícola stricto sensu é considerado um dos mais peculiares e estáveis existentes na biosfera. A capa rochosa que cobre e resguarda as cavernas das variações climáticas bruscas que ocorrem na superfície dá a esse ambiente uma série de características próprias, que condicionam a diversidade de vida animal e vegetal que se desenvolve em seu interior" (LINO, 2001, p. 203). Deste modo, as cavernas formam um ambiente único, com entrada de nutrientes dificultada e ausência total de luz nas zonas mais profundas, apresentando um microclima específico e ainda pouquíssimo estudado.

O estudo deste microclima é importante para compreender os fatores limitantes ao desenvolvimento e distribuição espacial da vida no ambiente cavernícola, o desenvolvimento dos espeleotemas e as alterações causadas pelo turismo. Também pode ajudar no entendimento dos processos de formação das cavernas e das mudanças climáticas globais, através de um estudo combinado com análises mineralógicas dos espeleotemas.

As visitas às unidades de conservação, em especial aos parques estaduais, tornaram-se uma atividade altamente disseminada nas últimas décadas, ocasionando a intensificação das visitas aos ambientes naturais protegidos. Grande parte desse

1 Parte de Dissertação de Mestrado defendida junto ao Programa de Pós-Graduação em Geografia Física da FFLCH-USP. 
fenômeno pode ser atribuída à disseminação do ecoturismo que pode vir a causar impactos negativos sobre o meio ambiente (SANO, 2007).

A exploração de cavernas é uma das formas de turismo associada a recursos geológicos mais difundida. Por isso, devem-se conhecer suas características ambientais para definir estratégias de gestão e conservação ambiental associada a seu uso turístico.

Devido a suas características físicas, as cavernas são ambientes únicos, com entrada de nutrientes dificultada e ausência total de luz nas zonas mais profundas, apresentando um microclima específico.

Entende-se por cavidade natural subterrânea "todo e qualquer espaço subterrâneo penetrável pelo ser humano, com ou sem abertura identificada, (...) incluindo seu ambiente, seu conteúdo mineral e hídrico, as comunidades bióticas ali encontradas e o corpo rochoso onde se inserem, desde que a sua formação tenha sido por processos naturais, independentemente de suas dimensões ou do tipo de rocha encaixante" (BRASIL, 2004). Resumidamente, entenderemos neste trabalho que "cavernas são cavidades naturais com dimensões que permitem acesso ao ser humano" (Karmann, 2003).

A iluminação e a presença de visitantes, dentre outras variáveis, modificam as condições ambientais das cavidades o que leva a uma degradação progressiva, favorecendo, inclusive, a destruição de espeleotemas. Estas variações ambientais correspondem a alterações na temperatura e umidade relativa do ar, na taxa de gás carbônico e na proliferação de algas.

Carvalho (2004) realizou um estudo de microclima subterrâneo na Gruta Olhos D'água, em Castro, PR. Neste trabalho foram realizadas medições de temperatura e umidade relativa do ar com uso de conjuntos psicrométricos, o que inviabiliza a detecção de eventuais influências da presença humana no ambiente de cavernas, pois as medidas só podem ser realizadas na presença do pesquisador.

Um estudo microclimático da Gruta Ubajara, CE, demonstrou que a temperatura e a umidade relativa do ar na entrada da caverna apresentam maiores variações do que em seu interior, sendo as flutuações maiores no período seco, comparado ao chuvoso (VERÍSSIMO et al., 2003). Neste trabalho também se evidenciou que os spots de iluminação contribuem para a elevação da temperatura do ar dos salões menores da caverna. Por esse motivo, em muitas cavernas, já há substituição dos spots por lâmpadas frias.

Longhitano et al. (2006) e Rocha et al. (2006) realizaram uma caracterização preliminar do microclima do ambiente de cavernas, através de um estudo de caso na Gruta Colorida do Parque Estadual de Intervales, SP. Nestes estudos foram utilizados cinco registradores de temperatura e umidade relativa do ar alocados ao longo da galeria superior da gruta (transeção da entrada até o final do corredor), durante período de dois dias. Percebeu-se um atraso na assimilação das mudanças do tempo exterior à medida que se adentra no interior da gruta. Também foi detectada uma variação da temperatura do ar no interior da gruta em função da presença humana.

O aumento da temperatura do ar decorrente da visitação turística foi apontado também nos trabalhos de Viana Júnior (2002) e Sánchez-Martos et al. (2002). No primeiro, as alterações de mais de $2^{\circ} \mathrm{C}$ foram registradas na caverna Santana do Parque Estadual Turístico do Alto Ribeira (PETAR), SP, na presença de três visitantes, sem uso de carbureteira. O segundo estudo foi realizado na caverna Cueva del Água de Iznalloz, em Granda, Espanha. Sánchez-Martos et al. (op. cit.) concluíram que a magnitude das alterações na temperatura do ar está diretamente relacionada com o número de visitantes e seu tempo de permanência na gruta e que a cavidade recupera-se termicamente poucas horas após a visita. 
Scaleante (2003) concluiu que o uso de carbureteiras é o principal fator responsável pela elevação da temperatura do ar em ambientes cavernícolas. Em sua dissertação, ele observou que a passagem de 310 visitantes pelo Salão do Encontro, na caverna Santana, SP, não provocou aumento na temperatura do ar, enquanto sete visitantes com carbureteira causaram o aumento de $4,5^{\circ} \mathrm{C}$. Além disso, quando o ambiente é impactado pela presença de visitantes usando iluminação a carbureto, a caverna demora mais tempo para se recuperar termicamente.

Sano (2007) aponta que "as cavernas são ambientes sensíveis à presença de visitantes em seu interior, pois há a alteração da temperatura, com o calor emitido pelo corpo humano, da umidade e da composição do ar por conta da respiração humana e do gás emitido pelas carbureteiras, que grudam nos espeleotemas e tiram a beleza natural com seu resíduo negro. Além disso, o número excessivo de pessoas caminhando no interior das grutas causa impactos no solo, que fica compactado, e, em alguns casos, podem deixar lixo, como resto de alimentos e garrafas".

Também, "a simples presença humana em ambientes cavernícolas, desde que em quantidade superior àquela que o sistema é capaz de absorver, provoca impactos irreversíveis sobre a biota, o maciço rochoso e as formações internas" (SCALEANTE, 2003).

Tendo em vista a importância do tema, os objetivos desta pesquisa foram: caracterizar o microclima do ambiente de caverna em condições naturais, elencar características físicas da cavidade que influenciem em seu microclima e detectar possíveis alterações microclimáticas ocorridas no ambiente cavernícola em decorrência das visitas turísticas.

Assim, registraram-se, inicialmente, nesse estudo, as condições ambientais naturais da caverna, o que permitirá detectar as possíveis perturbações ambientais que grupos humanos produzem no interior desta. Foram analisadas as variações espaciais e temporais dos atributos em função do número de visitantes e tempo de permanência nas cavernas, da capacidade de ventilação natural da gruta, do grau de gotejamento e das dimensões e formas dos salões.

\section{Área de estudo}

A região escolhida para esta pesquisa foi o Vale do Rio Ribeira de Iguape, que apresenta a maior importância espeleológica das regiões Sul e Sudeste do Brasil (LINO, 2001). Situa-se em uma área de formações calcárias revestidas por floresta ombrófila mista, relevo orogênico com serras em forma de crista e escarpas assimétricas (SÃO PAULO, 1994). O clima meridional é permanentemente úmido, caracterizando-se por uma unidade rítmica com entrada de massas polares e passagens de sistemas frontais frequentes, inclusive no verão (MONTEIRO, 1973).

Nessa região, situa-se o Parque Estadual Intervales (PEI), situado a $270 \mathrm{~km}$ da capital, abrangendo os municípios de Guapiara, Ribeirão Grande, Sete Barras, Eldorado e Iporanga, no divisor de águas das bacias do Paranapanema e Ribeira de Iguape (SÃO PAULO, 2009). 


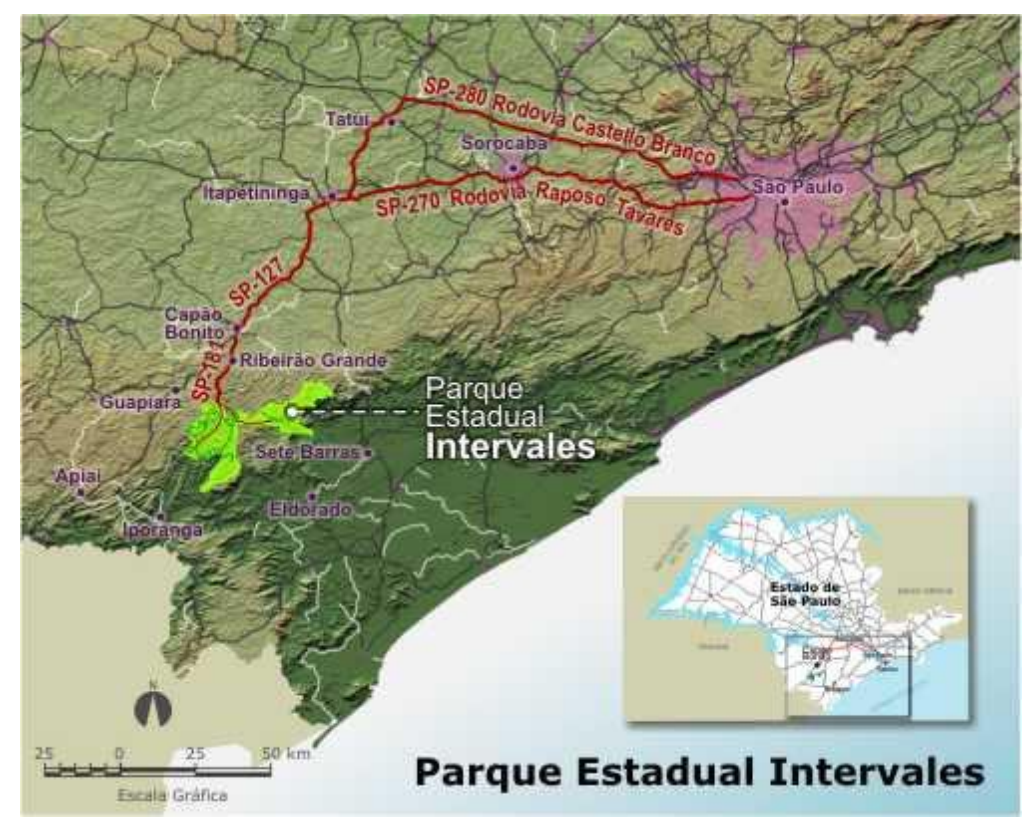

Figura I

\section{Localização do Parque Estadual de Intervales, SP}

Fonte: Atlas de Intervales. Disponível em:

http://www.geografia.fflch.usp.br/mapas/Atlas_Intervales/oparque.html

O Parque Estadual Intervales possui dezenas de cavernas, formadas a partir da dissolução do calcário. As cavernas resultam da ação e circulação da água sobre rochas solúveis.

Segundo Karmann (2003), as cavernas carbonáticas são formadas a partir da dissolução da calcita (carbonato de cálcio - $\mathrm{CaCO}_{3}$ ) pelo ácido carbônico $\left(\mathrm{H}_{2} \mathrm{CO}_{3}\right)$. O ácido carbônico forma-se quando a água da chuva percola pelo solo da região, rico em matéria orgânica, cuja decomposição gera dióxido de carbono (CO2).

A água acidificada penetra pelas fendas do calcário atacando a rocha e produzindo o bicarbonato de cálcio [Ca(HCO3)2], que é solúvel e facilmente transportado pela água. As fendas alargam-se lentamente, formando as cavidades subterrâneas.

Quando a caverna já está formada, o bicarbonato de cálcio transportado emerge no teto da caverna até atingir volume e peso suficiente para cair. Nesse momento, ocorre a liberação do gás carbônico e precipitação do carbonato de cálcio, que darão origem as estalactites.

Assim, condicionantes geológicas, geomorfológicas, climáticas e da vegetação agem de forma conjunta e articulada no processo de espeleogênese. Este é um processo dinâmico e as cavernas dela originadas devem ser entendidas não como produtos acabados, mas sim como componentes subterrâneos de um relevo em contínua evolução.

Devido a essas condições, o Vale do Ribeira é a área de maior importância espeleológica das regiões sudeste e sul do Brasil, abrangendo porções dos estados do Paraná e São Paulo (LINO, 2001) 
A gruta da Santa, localizada no agrupamento Bocaina-Lageado do Parque Estadual de Intervales, foi a escolhida para esta pesquisa. Tal caverna possui algumas estalactites e represas de travertino no piso. Seu ambiente é relativamente seco, pois apresenta pequeno grau de gotejamento dos espeleotemas e um riacho de águas calmas, o que proporciona a presença de morcegos e opilhões. Uma imagem de Nossa Senhora de Lourdes está presente em sua entrada, junto a um altar, conferindo um uso turístico de cunho religioso à gruta (figura II). A Gruta da Santa apresenta uma única entrada de grande amplitude o que the confere boa ventilação. Constitui-se de uma única galeria, com corredores amplos. Um pequeno curso d'água corre em parte de seu interior.

\section{Material e métodos}

O procedimento técnico para o estudo deuse na forma de coletas sistemáticas de

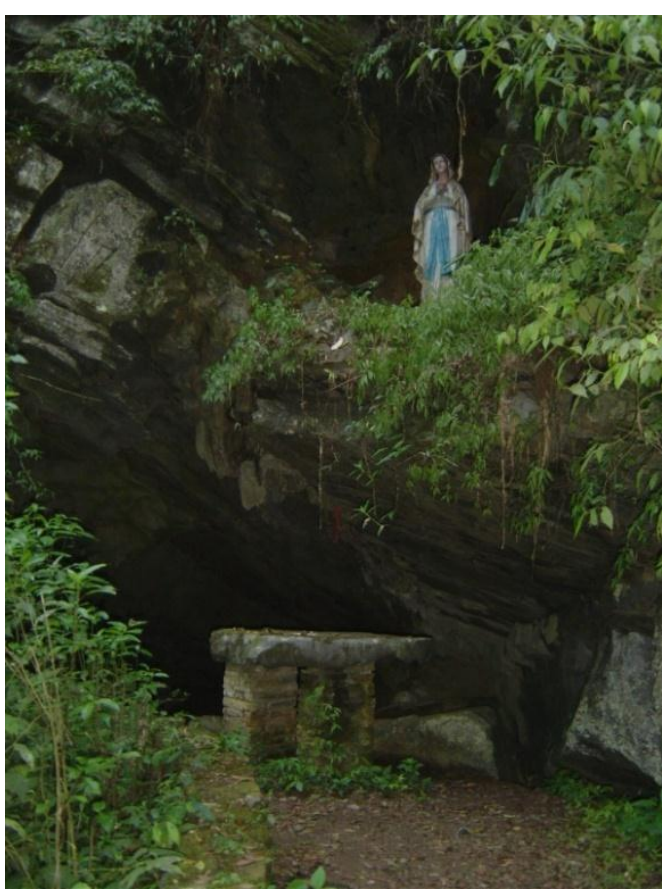

Figura II: Entrada da Gruta da Santa dados, através de trabalho de campo.

A caverna pesquisada foi a gruta da Santa, do agrupamento Bocaina/ Lageado (PEI). A escolha dessa caverna seguiu a proposta dos Planos de Manejo Espeleológico do Estado de São Paulo que considera essa caverna como uma das de maior visitação no parque. Portanto, é objeto de plano de uso público.

A elaboração de trabalhos de campo permitiu a instalação e retirada dos sensores registradores de temperatura e umidade relativa do ar e a coleta dos dados referentes à concentração de gás carbônico. Nesta etapa, foram instalados três termohigrômetros na cavidade, sendo um na entrada (caracterização de microclima transicional), outro em um salão dentro do circuito tradicional de visitação e o terceiro em um trecho sem visitação, porém periférico a uma área visitável. Os equipamentos utilizados no monitoramento da caverna apresentavam sensibilidade e precisão suficientes para registrar pequenas variações. A tabela I apresenta os equipamentos utilizados e suas características.

Tabela I

\section{Equipamentos utilizados}

\begin{tabular}{ccccc}
\hline Instrumento & Marca & Modelo & Precisão & Acurácia \\
\hline $\begin{array}{c}\text { termohigrômetros } \\
\begin{array}{c}\text { Sensor de gás } \\
\text { carbônico }\end{array}\end{array}$ & Onset & Stow Away & 0,1 & $0,2{ }^{\circ} \mathrm{C}(\mathrm{T}) \mathrm{e}$ \\
$2,5 \%(\mathrm{UR})$ \\
\end{tabular}

O monitoramento da caverna foi realizado durante período de uma semana (sete dias) com resolução temporal dos termohigrômetros de seis minutos. O objetivo foi 
mostrar as variações naturais dos atributos do clima (períodos com ausência de visitação - situação controle), e o impacto da visitação. Para o segundo caso, foram realizadas visitas simuladas com grupos que reproduzissem o número, o tempo de permanência e o comportamento dos visitantes tradicionais. Os trabalhos de campo para instalação e retirada dos aparelhos ocorreram entre 14 e 20 de fevereiro de 2009.

A atividade de visitação na caverna foi realizada por meio de um questionário, onde constavam: data e horário de entrada e de saída dos visitantes, quantidade de visitantes e quantidade de carbureteiras e de lanternas utilizadas pelos turistas.

Os dados de gás carbônico foram colhidos em vários pontos de cada caverna (mínimo de dez amostras), englobando todo o circuito tradicional de visitação.

Após a coleta dos dados, foram confeccionados perfis térmicos, higrométricos e de dióxido de carbono $\left(\mathrm{CO}_{2}\right)$. Além dos perfis, a temperatura e umidade relativa do ar também foram analisadas a partir de parâmetros estatísticos (média, máximo, mínimo, amplitude, moda, variância e desvio padrão), com destaque para as amplitudes registradas nos períodos com visitação. O estudo da moda, valor que surge com mais frequência nas amostras, é importante neste trabalho, pois mostra o valor de temperatura e umidade que se espera encontrar nas cavernas em que há estabilidade microclimática. A mediana também ajuda a detectar climas estáveis, pois, quando a distribuição dos dados é simétrica, a média e a mediana coincidem.

A partir dos dados de gás carbônico, foram gerados gráficos de linha, mostrando a variação do parâmetro da entrada da caverna até o seu término.

No ambiente externo, próximo na sede do Parque Estadual Intervales, foi instalada uma estação meteorológica automática composta por sensores registradores de temperatura do ar, umidade relativa do ar, direção e velocidade do vento, chuva e radiação solar. O uso desses equipamentos justifica-se para controle climático do ambiente externo e comparação com os dados obtidos no interior da gruta. Todos os dados obtidos foram calibrados para serem utilizados.

Cabe ressaltar, no entanto, que a metodologia para este estudo apresenta algumas limitações, pois o período de monitoramento climático não permite compreender as alterações sazonais naturais do clima do ambiente de cavernas.

Os pontos de monitoramento de temperatura e umidade relativa do ar na Gruta da Santa podem ser visualizados na figura III. Os dados foram colhidos entre os dias 14 e 20 de fevereiro de 2009. 


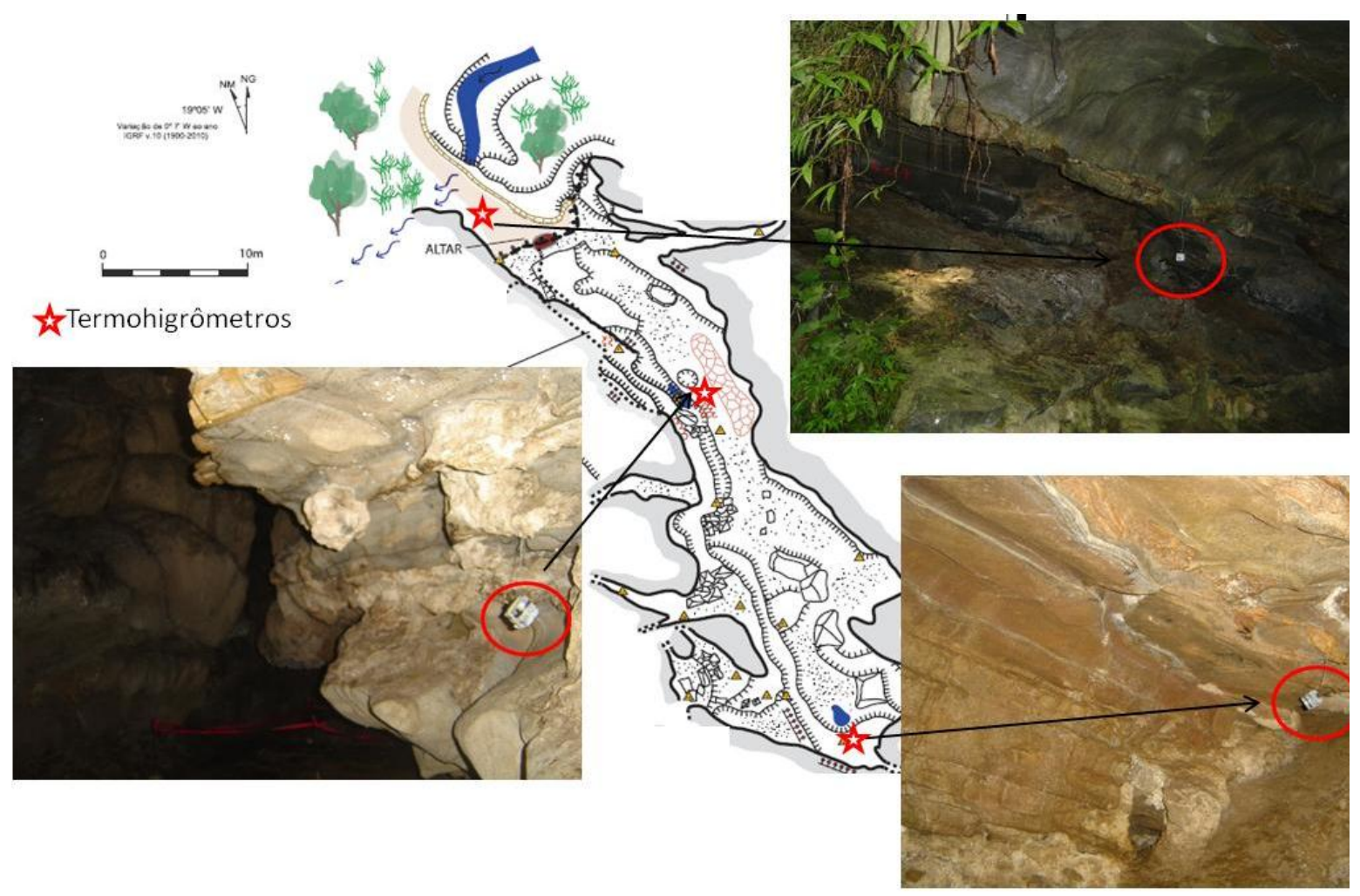

Figura III

\section{Localização dos termohigrômetros na Gruta da Santa}

Organização e fotografias: Bárbara N. Rocha, 2010. Fonte: Instituto EKOS, 2009.

O primeiro termohigrômetro foi instalado na entrada da gruta, próximo ao altar da Santa. Como a entrada da caverna é ampla e a vegetação a sua frente é composta principalmente por grama baixa, este local recebe radiação solar direta e difusa. A boca voltada para o norte permite com que a radiação incida durante todo o dia.

O próximo local de monitoramento fica no meio da cavidade, no circuito tradicional de visitação, próximo ao curso d'água e a um travertino. Neste local, os visitantes param para admirar o espeleotema, sendo, assim, um local de grande visitação.

O último termohigrômetro foi instalado no final do duto, em uma zona afótica e pouco ventilada, onde não há visitação turística.

\section{Resultados e discussão}

A tabela II apresenta alguns parâmetros estatísticos, calculados a partir dos dados de temperatura e umidade relativa do ar colhidos ao longo da semana. Os parâmetros escolhidos para análise foram: média, máximo, mínimo, amplitude, moda, variância e desvio padrão.

A menor média térmica $\left(16,7^{\circ} \mathrm{C}\right)$ foi registrada na entrada da caverna, devido às maiores flutuações ambientais neste ponto. Aí também foram encontrados o máximo e o mínimo valor do período $\left(19,4^{\circ} \mathrm{C}\right.$ e $14,1^{\circ} \mathrm{C}$, respectivamente), resultando na maior amplitude térmica $\left(5,3^{\circ} \mathrm{C}\right)$. Essas variações resultam da radiação incidente durante o dia e da perda de calor durante a noite, visto que não há proteção rochosa neste local.

No salão visitável, localizado no meio da galeria, a temperatura média foi de $17,2^{\circ} \mathrm{C}$, com máxima de $17,5^{\circ} \mathrm{C}$ e mínima de $17^{\circ} \mathrm{C}$, resultando numa amplitude de $0,5^{\circ} \mathrm{C}$. No final do corredor, onde não ocorre visitação, a média foi de $17,1^{\circ} \mathrm{C}$, a máxima de $17,3^{\circ} \mathrm{C}$ e a mínima de $16,7^{\circ} \mathrm{C}$. Apesar de estar mais distante da entrada, este ponto 
apresentou amplitudes térmicas mais elevadas que o ponto anterior, pois aquele está próximo a um corpo d'água, que ajuda a minimizar as flutuações ambientais.

Tabela II

\section{Parâmetros estatísticos da temperatura e umidade relativa do ar da Gruta da Santa (período de 14 a 20/02/2009)}

\begin{tabular}{|l|lll|lll|}
\cline { 2 - 7 } \multicolumn{1}{c|}{} & \multicolumn{3}{l|}{ Temperatura do ar $\left({ }^{\circ} \mathrm{C}\right)$} & \multicolumn{3}{l|}{ Umidade relativa do ar (\%) } \\
\cline { 2 - 7 } \multicolumn{1}{c|}{} & Entrada & $\begin{array}{l}\text { Salão } \\
\text { Visitável }\end{array}$ & $\begin{array}{c}\text { Salão não } \\
\text { Visitável }\end{array}$ & Entrada & $\begin{array}{l}\text { Salão } \\
\text { Visitável }\end{array}$ & $\begin{array}{c}\text { Salão não } \\
\text { Visitável }\end{array}$ \\
\hline Média & 16,7 & 17,2 & 17,1 & 99,9 & 100,0 & 100,0 \\
Máximo & 19,4 & 17,5 & 17,3 & 100,0 & 100,0 & 100,0 \\
Mínimo & 14,1 & 17,0 & 16,7 & 68,4 & 100,0 & 100,0 \\
Amplitude & 5,3 & 0,5 & 0,7 & 31,6 & 0,0 & 0,0 \\
Moda & 16,8 & 17,3 & 17,2 & 100,0 & 100,0 & 100,0 \\
Variância & 1,4 & 0,0 & 0,0 & 2,8 & 0,0 & 0,0 \\
Desvio & 1,2 & 0,1 & 0,1 & 1,7 & 0,0 & 0,0 \\
padrão & 1,2 & 0,0 & & & \\
\hline
\end{tabular}

Organização: Bárbara N. Rocha, 2010.

As modas estiveram próximas das médias, conferindo estabilidade aos dados. Isso se comprova também pelos baixos valores de variância e desvio padrão.

A umidade relativa do ar apresentou-se ainda mais estável. Nos pontos interiores à caverna, o ar sempre esteve saturado, resultando em médias, máximos, mínimos, modas e medianas iguais a $100 \%$ e, consequentemente, amplitudes, variâncias e desvios padrões nulos.

$\mathrm{Na}$ entrada da caverna, os dados apresentaram algumas variações, apesar de a média estar muito próxima do ponto de saturação $(99,9 \%)$ e a moda ser de $100 \%$. A menor UR registrada neste local foi de $68,4 \%$, resultando em amplitude de 31,6 . A variância foi de 2,8 e o desvio padrão de 1,7 . Isso se explica pela localização deste posto de coleta no meio externo, sujeito as variações do ciclo diuturno da temperatura.

O gráfico abaixo (figura VI) mostra a variação da temperatura do ar no meio externo (estação meteorológica e entrada da gruta - eixo da esquerda) e no interior da gruta (salões visitável e não visitável - eixo da direita). 


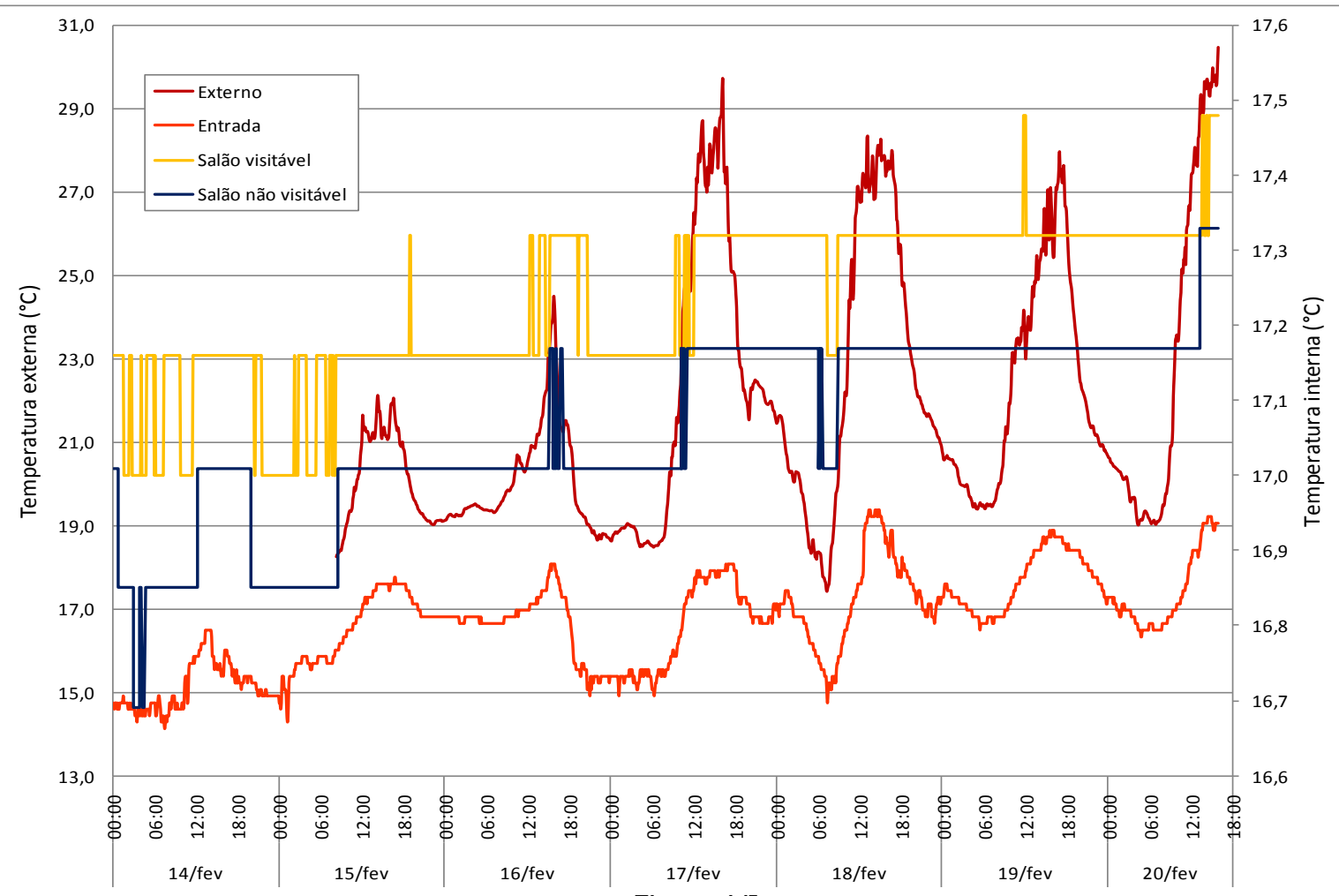

Figura VI

Variação da temperatura do ar $\left({ }^{\circ} \mathrm{C}\right)$ na Gruta da Santa

Organização: Bárbara N. Rocha, 2010.

Na gruta, o local que apresentou as maiores variações de temperatura foi a entrada devido a incidência de radiação solar direta e difusa neste ponto. Os valores acompanham claramente o ciclo entre o dia e a noite, com menores amplitudes térmicas, mas sem atrasos nas assimilações do tempo exterior.

No meio interno, as variações são pequenas, inferiores a $0,5^{\circ} \mathrm{C}$, seguindo a tendência de elevação ou diminuição ditadas pelo meio externo. Porém, essa assimilação do tempo exterior apresenta atrasos e não pode ser percebida todos os dias. O salão visitável apresentou temperaturas cerca de $0,2^{\circ} \mathrm{C}$ mais elevadas que as do final da galeria durante todo o período. Esses dados corroboram os estudos de Longhitano et al. (2006), Rocha et al. (2006) e Veríssimo et al. (2003), que demonstram que a temperatura do ar na entrada da caverna apresentam maiores variações do que em seu interior, onde esses parâmetros tendem à estabilidade.

No dia 14, primeiro dia de registros, um grupo de três pessoas visitou a caverna, das $13 \mathrm{~h} 55 \mathrm{~min}$ às $14 \mathrm{~h} 10 \mathrm{~min}$. Foi utilizada iluminação de lanternas e leds pelos turistas, pois as carbureteiras foram proibidas no parque. Neste momento, as temperaturas no interior da cavidade não apresentaram nenhuma alteração, permanecendo constante em $17,2^{\circ} \mathrm{C}$ no salão visitável, desde às $11 \mathrm{~h} 30 \mathrm{~min}$ até às $20 \mathrm{~h} 20 \mathrm{~min}$, e em $17^{\circ} \mathrm{C}$ na área não visitável (figura V). 


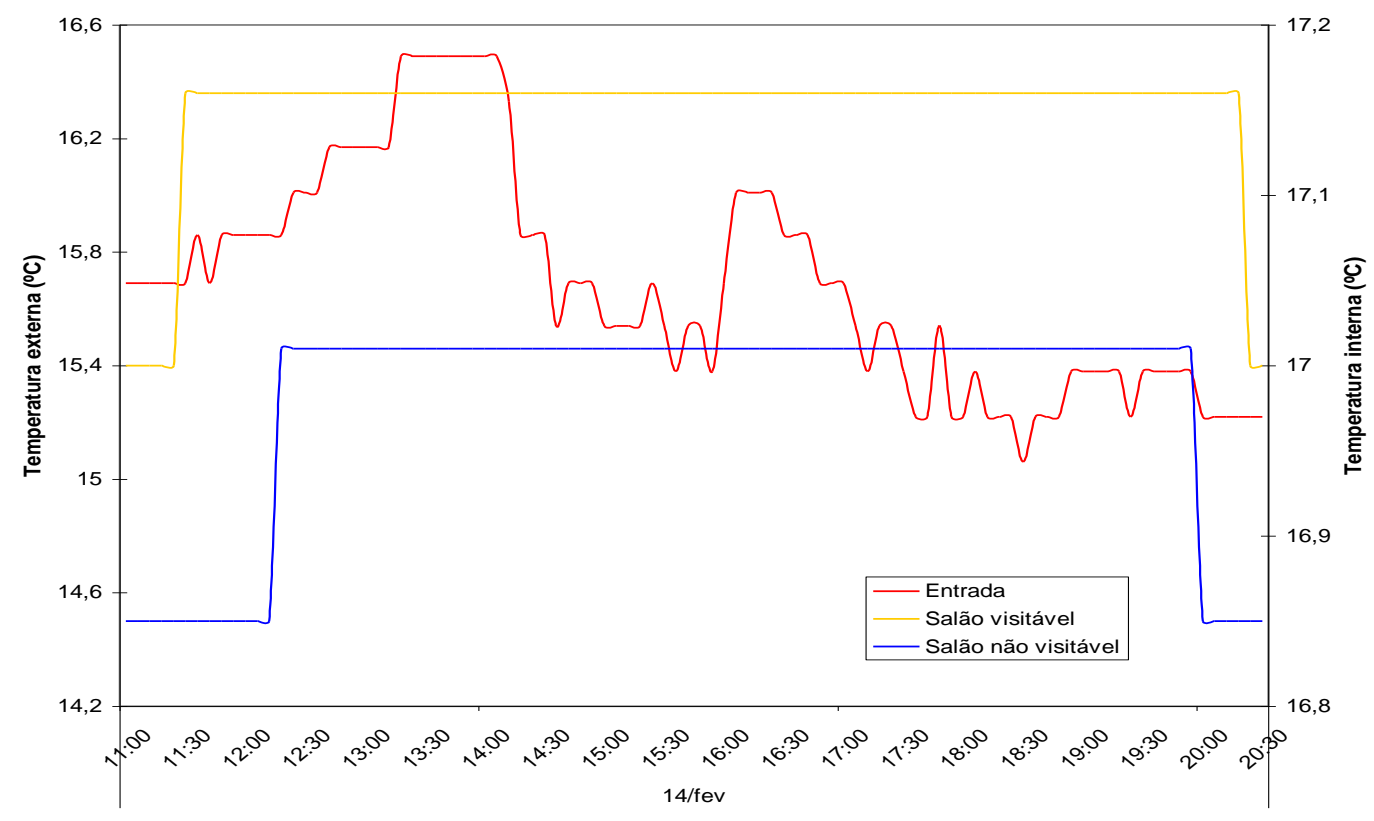

Figura $\mathrm{V}$

Variação horária da temperatura do ar no dia 14 de fevereiro na Gruta da Santa Organização: Bárbara N. Rocha, 2010.

Portanto, mesmo apresentando certa estabilidade microclimática, grupos pequenos de visitantes não devem provocar alterações na temperatura do ar do interior da gruta da Santa. A variação da umidade relativa do ar pode ser vista na figura VI a seguir.

No interior da caverna, tanto no salão visitável quanto no não visitável, a umidade relativa do ar manteve-se constante em $100 \%$. Variações puderam ser percebidas somente na entrada da cavidade, nos dias 17 e 18 de fevereiro. As quedas da UR na entrada da caverna não acompanharam as variações registradas pela estação meteorológica, que apresentaram aumento nesses momentos. Os dados de radiação solar global e de velocidade do vento explicam essas oscilações (figuras VII e VIII). 


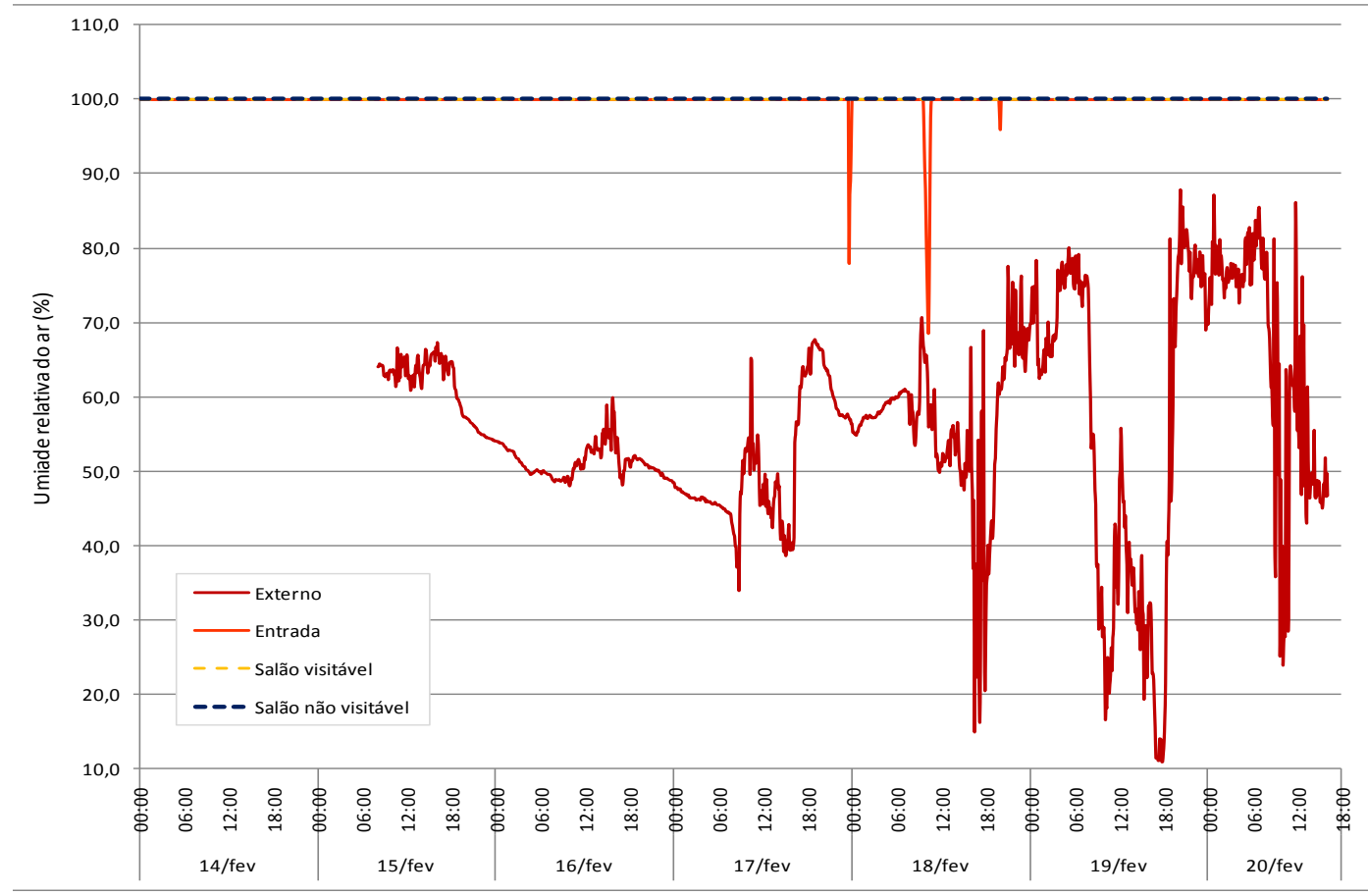

Figura VI

Variação da umidade relativa do ar (\%) na Gruta da Santa Organização: Bárbara N. Rocha, 2010.

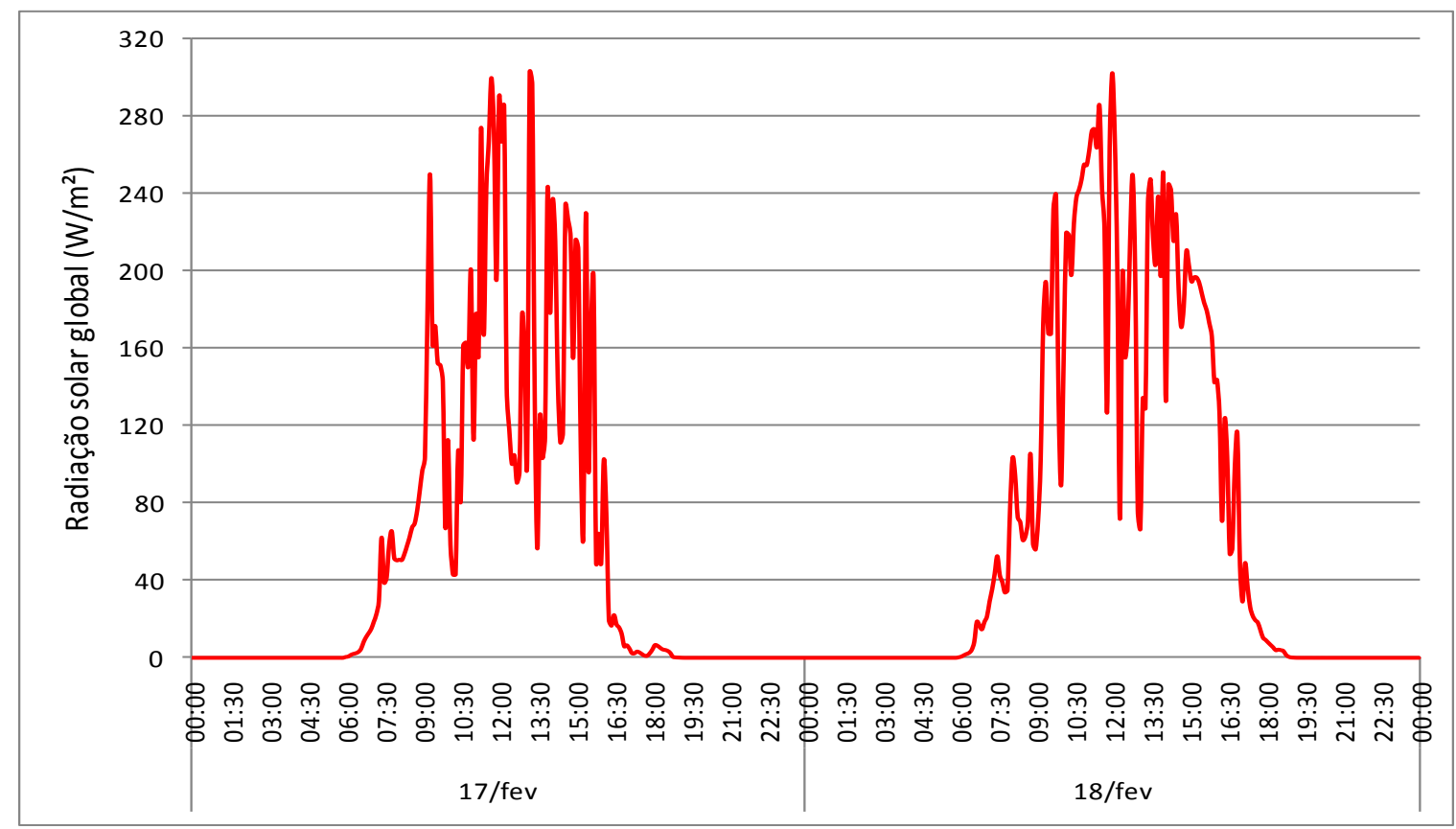

Variação da radiação solar global na Estação meteorológica automática instalada no P.E. Intervales

Organização: Bárbara N. Rocha, 2010. 


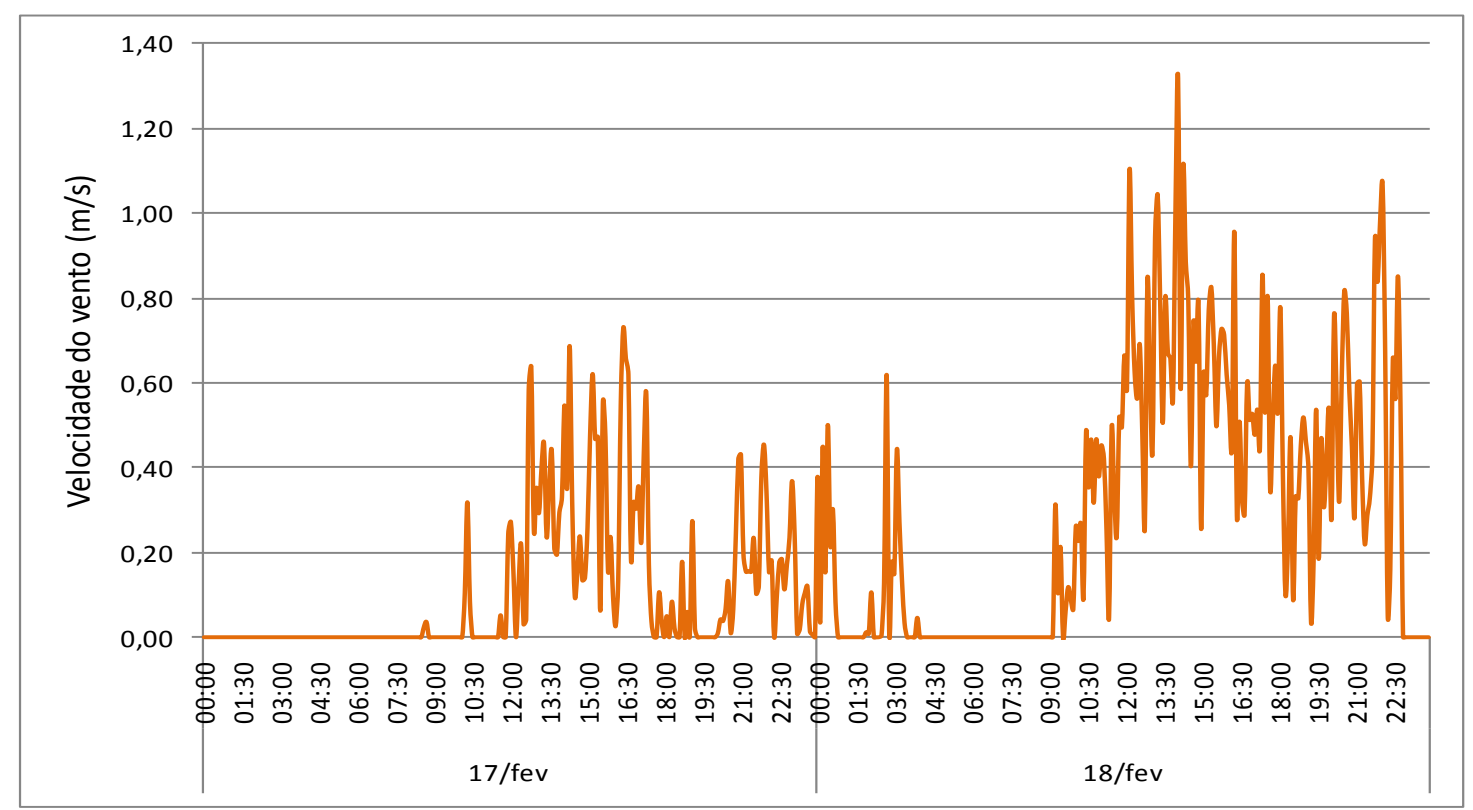

Figura VIII

Velocidade do vento na Estação meteorológica automática instalada no P.E. Intervales

Organização: Bárbara N. Rocha, 2010.

Por volta de $13 \mathrm{~h}$ do dia 17 de fevereiro de 2010, o vento passou a apresentar velocidades mais elevadas e provenientes de direção Sudeste. Isso combinado com a orientação da abertura da caverna pode ter contribuído para uma renovação do ar na entrada da gruta, o que pode ter reduzido a umidade relativa do ar neste ponto. Como a entrada da caverna é descampada, ventos podem atingi-la de qualquer direção.

No dia 18, a umidade da entrada diminui por volta das 11 h00min da manhã, momento em que a radiação solar direta atingiu seus máximos valores naquele dia. Ventos vindos do Sul também passaram a soprar com maior intensidade neste horário. As variações da UR na entrada da caverna explicam-se, portanto, por fatores naturais.

A figura IX apresenta o perfil de dióxido de carbono da Gruta da Santa realizado no dia 20 de fevereiro às 09 h00min, na presença de quatro pessoas.

No meio externo, a concentração de gás carbônico é menor (373 ppm) e aumenta gradativamente a medida em que se interioriza no duto, atingindo $499 \mathrm{ppm}$ ao final da galeria.

Comparado a estudos de gás carbônico feito em outras grutas do mesmo parque, esta variação de $126 \mathrm{ppm}$ pode ser considerada pequena. Foi a menor amplitude encontrada nas cavernas do Parque Estadual de Intervales (ROCHA, 2010).

A taxa de $\mathrm{CO}_{2}$ no interior da gruta é baixa, pois praticamente inexistem espeleotemas na caverna. A formação desses ornamentos é a principal responsável pela liberação do referido gás na atmosfera cavernícola, como descrito por Karmann (2003). 


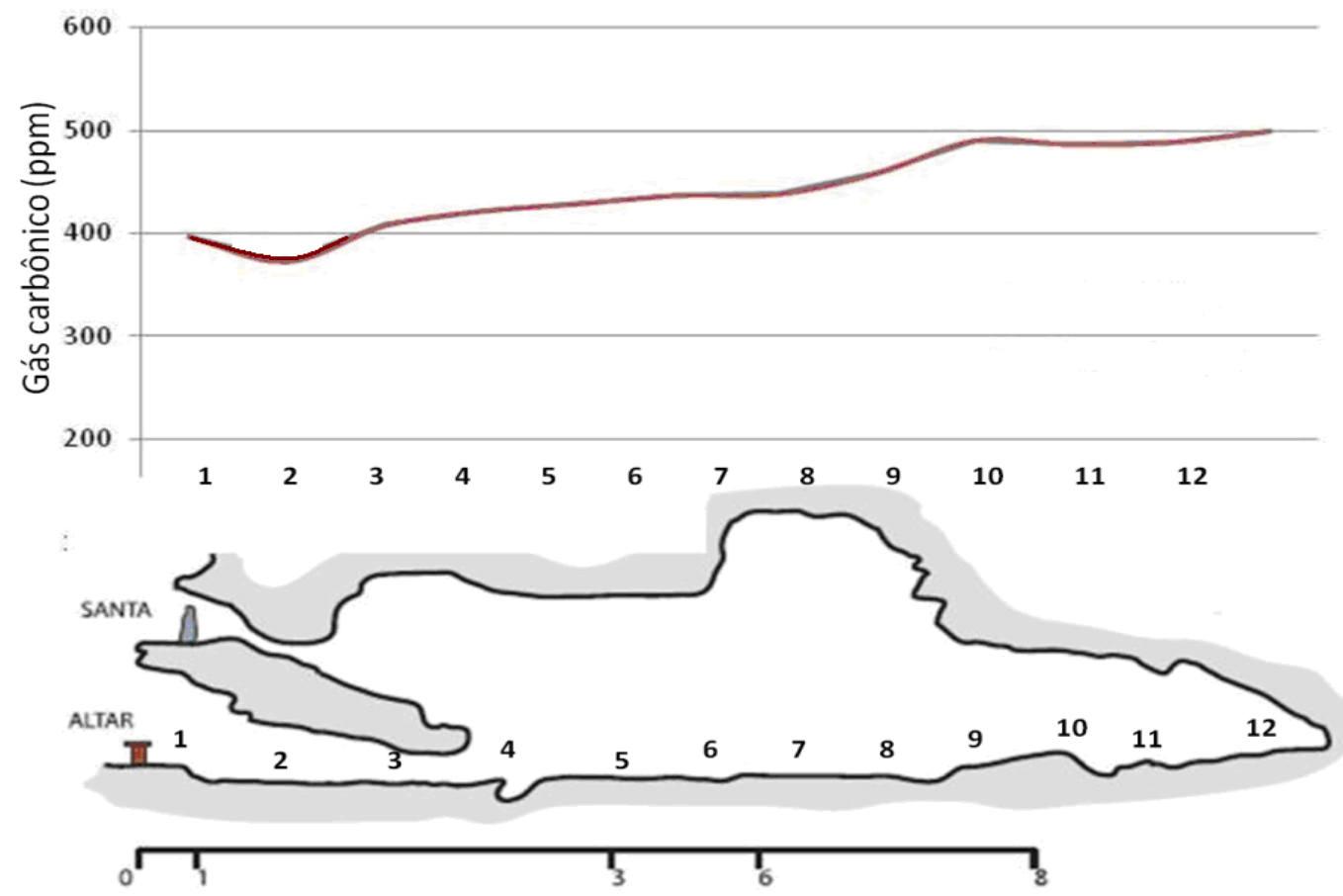

Figura IX

Perfil de gás carbônico da Gruta da Santa

Organização: Bárbara N. Rocha, 2010.

\section{Considerações Finais}

Este estudo permite concluir que o microclima da gruta da Santa caracteriza-se por uma elevada umidade relativa do ar, atingindo a saturação, e temperatura tendendo a estabilidade na medida em que se adentra em seu interior. Essa estabilidade decorre da ausência de claraboias e rios caudalosos que facilitam a circulação do ar em ambientes fechados. Há, nessa gruta, somente uma ligeira troca energética entre os meios externo e interno.

A concentração de gás carbônico é maior no interior da cavidade, comparado ao meio externo. A pequena quantidade de espeleotemas nessa caverna contribui para que as taxas de gás carbônico não sejam elevadas em seu interior.

A gruta da Santa não apresentou alterações atmosféricas em decorrência da visitação turística por um grupo pequeno. Não foram identificadas variações térmicas e hígricas, bem como na concentração de $\mathrm{CO}_{2}$. Seu pórtico e corredores amplos facilitam a dispersão do calor humano no interior dessa gruta.

Acredita-se que este trabalho possa contribuir para melhor entendimento deste ambiente único e carente de estudos que são as cavernas. Ressalta-se, no entanto, que esta pesquisa não esgota o tema. Muito ainda há de ser estudado para que possamos compreender o ritmo do microclima cavernícola. O intervalo de tempo adotado para registrar os atributos do clima nesta pesquisa (uma semana) não permite compreender a sazonalidade climática das grutas. Estudos com análises em maior período de tempo são sugeridos para futuras pesquisas. Outros trabalhos também podem buscar identificar a capacidade de suporte das grutas, considerando seus aspectos microclimáticos. 


\section{Agradecimentos}

Agradecemos ao CNPQ - Conselho Nacional de Desenvolvimento Científico e Tecnológico - pelo auxílio na compra de equipamentos (processo número 485935/2007-4 do edital Universal MCT/CNPq 15/2007); à CAPES - Coordenação de Aperfeiçoamento de Pessoal de Nível Superior - pela concessão de bolsa de estudo; ao Instituto Florestal/SMA pela autorização do projeto (processo SMA número 260108 - 001.150/ 2008); ao Sr. Eliseu, guia turístico do Parque Estadual Intervales, que cuidou da estação meteorológica, anotou os visitantes do parque e nos acompanhou nos trabalhos de campo; e ao Rogério Rozolen Alves, técnico de laboratório de climatologia da FFLCH-USP, que ajudou na instalação e calibragem da estação meteorológica.

\section{Referências bibliográficas}

.BRASIL. Resolução CONAMA no 347. 2004

.CARVALHO, S. M. Estudo de microclima subterrâneo: o exemplo da Gruta Olhos D'água - Castro (PR). In: ZAVATTINI, J. A. Estudos do clima no Brasil. São Paulo: Alínea editora, 2004. p. 212-213.

.LINO, C. F. Cavernas: o fascinante Brasil subterrâneo. São Paulo: Gaia, 2001.

.LONGHITANO, G. A., ROCHA, B. N. e ÂNGELO FURLAN, S. Caracterização microclimática da Gruta Colorida - Parque Estadual de Intervales, SP. In: Anais do VII Simpósio Brasileiro de Climatologia Geográfica. Rondonópolis, 2006.

.MONTEIRO, C. A. de F. A dinâmica climática e as chuvas no Estado de São Paulo. Atlas. São Paulo, Instituto de Geografia/USP, 1973. 129p.

.ROCHA, B. N. Estudo microclimático do ambiente de cavernas, Parque Estadual Intervales, SP. São Paulo: USP, 2010. Dissertação (mestrado).

.ROCHA, B. N., LONGHITANO, G. A. e ÂNGELO FURLAN, S. Levantamento climáticofaunístico da Gruta Colorida do Parque Estadual de Intervales. In: Anais do IV Congresso Brasileiro de Biometeorologia. Ribeirão Preto, 2006.

.SÁNCHEZ-MARTOS, F., CALAFORRA, J. M., FERNÁNDEZ-CORTES, A. e GONZÁLES-RÍOS, M. J. Experiência de visitas masivas a cavidades em condiciones naturales: la Cueva del Água de Iznalloz (Granada). Geogaceta, 31, 2002. P. 23-26.

.SANO, N. N. Estudo comparado da gestão das visitações nos Parques Estaduais Turísticos do Alto Ribeira (PETAR) e Intervales (PEI). Dissertação (mestrado). São Paulo: USP, 2007. 100p. (+ anexos).

.SCALEANTE, J. A. B. Avaliação do impacto de atividades turísticas em cavernas. Dissertação (mestrado). Campinas: UNICAMP, 2003. 70p. (+ anexos).

.SÃO PAULO (Estado). Parque Estadual Intervales: plano de gestão ambiental fase 1. 1994.

.SÃO PAULO (Estado). Parque Estadual Intervales: plano de manejo. 2009.

.KARMANN, Ivo. Ciclo da água: água subterrânea e sua ação geológica. In: TEIXEIRA, W., Decifrando a Terra. Oficina de textos: São Paulo, 2003.

.VERÍSSIMO, C. U., SOUSA, A. E. B. A. de, RICARDO, J. M., BARCELOS, A. C., NOGUEIRA NETO, J. de A., REIS, M. G. M. Microclima e espeleoturismo na gruta de Ubajara, CE. In.: Anais... 27 Congresso Brasileiro de Espeleologia. Januária, 2003.

.VIANA JUNIOR, O. Hidroquímica, hidrologia e geoquímica isotópica (O e H) da fácie de percolação vadosa autogênica, Caverna Santana, município de Iporanga, Estado de São Paulo. Dissertação (mestrado). São Paulo: Instituto de Geociências/ USP, 2002. 113p. 